\title{
A (HÁ) LIBERDADE DE EXPRESSÃO NA SOCIEDADE EM REDE \\ (?): MANIPULAÇÃO NA ERA DIGITAL
}

\author{
IS THERE FREEDOM OF EXPRESSION ON THE NETWORK \\ SOCIETY? MANIPULATION IN THE DIGITAL AGE
}

\section{LA (ALLÍ) LIBERTAD DE EXPRESIÓN EN LA SOCIEDAD DE LA RED (?): MANIPULACIÓN EN LA EDAD DIGITAL}

\author{
Lucas Gonçalves da Silva ${ }^{1}$ \\ Alessandra Cristina de Mendonça Siqueira²
}

\begin{abstract}
Resumo
Novo modelo de transformação social, a tecnologia se encontra no cerne das influentes modificações. Em um contexto de uma sociedade sempre mais conectada, as fronteiras começam a se mitigar, e o conceito de tempo também sofre disparidades, ante a velocidade das informações, denominando essa nova configuração social de "Sociedade em Rede" termo cunhado pelo sociólogo Manuel Castells. A internet se configura como a grande tecnologia desses tempos, e quanto mais "eus virtuais" estão no ciberespaço, mais a sociedade também se demonstra vulnerável ante as novas constatações. Nesse toar, encontra-se a importância a ser dada à proteção de dados pessoais no âmbito virtual. Sem que haja essa proteção, o indivíduo se coloca como hipossuficiente ante a manipulação no ciberespaço.
\end{abstract}

Palavras-chave: Cibernética. Sociedade em Rede. Liberdade de Expressão. Autodeterminação informativa. Privacidade.

\footnotetext{
${ }^{1}$ Pós-doutor em Direito pela Universidade Federal da Bahia e pela Università Degli Studi G. d'Annunzio (Itália). Doutor e Mestre em Direito do Estado pela Pontifícia Universidade Católica de São Paulo PUC/SP. Professor Associado da Graduação em Direito e do Programa de Mestrado em Direito da Universidade Federal de Sergipe. Vice-Presidente do Conselho Nacional de Pesquisa e Pós-Graduação em Direito CONPEDI.

${ }^{2}$ Mestranda em Direito pela Universidade Federal de Sergipe. Pós-Graduada em Direito Constitucional e Administrativo pela Escola Paulista de Direito. Coordenadora do Aracaju Legal Hackers e membro do IBDEE e da Internet Society. Servidora do TJSE.
} 


\begin{abstract}
A new model of social transformation, technology is at the heart of influential changes. In the context of an increasingly connected society, borders are beginning to be mitigated, and the concept of time also suffers from disparities, given the speed of information, calling this new social configuration "Networked Society" a term coined by sociologist Manuel Castells. The Internet is configured as the great technology of these times, and the more "virtual selves" are in cyberspace, the more society is also vulnerable to the new findings. The importance to be given to the protection of personal data in the virtual environment is to be found in this toar. Without such protection, the individual is placed as hyposuffient in the face of manipulation in cyberspace.
\end{abstract}

Keywords: Cybernetics. Network Society. Freedom of Expression. Information selfdetermination. Privacy.

\title{
RESUMEN
}

Un nuevo modelo de transformación social, la tecnología está en el centro de los cambios influyentes. En el contexto de una sociedad cada vez más conectada, las fronteras empiezan a atenuarse, y el concepto de tiempo también sufre disparidades, dada la velocidad de la información, denominando a esta nueva configuración social un término de "Sociedad en Red" acuñado por el sociólogo Manuel Castells. La Internet se configura como la gran tecnología de estos tiempos, y cuanto más "yos virtuales" haya en el ciberespacio, más vulnerable se muestra la sociedad ante los nuevos descubrimientos. La importancia que se debe dar a la protección de los datos personales en el ámbito virtual se encuentra en esto. Sin esta protección, el individuo se coloca a sí mismo como hiposuficiente frente a la manipulación en el ciberespacio.

Palabras clave: Cibernética. Sociedad de la Red. Libertad de expresión. Autodeterminación de la información. Privacidad.

\section{INTRODUÇÃO}

Quando autores como George Orwell e Isaac Asimov trataram temas como "vigilância" e "robôs", eles foram colocados em um contexto de ficção científica com 
poucas possibilidades de se tornarem realidade. A ideia de um Big Brother que visse e ouvisse a todos, uma demonstração factual do modelo panóptico, era muito longe de qualquer sistema que pudesse a existir.

No entanto, com o vislumbre dos primeiros modelos tecnológicos postos em realidade, e a implicação de que poderia vir a existir tecnologias que usassem a premissa de inteligência artificial, máquinas com redes neurais semelhantes àquelas do gênero humano, computadores com capacidades de processamento muito maiores do que se poderia vislumbrar, as ideias de Asimov e Orwell não parecem mais uma sombra ficcional, e sim, uma realidade que já está se descortinando.

A ideia sistemática de vigilância governamental, por exemplo, encontra-se em pleno funcionamento, especialmente em países como a China, onde o governo exerce o controle de seus cidadãos, utilizando ferramentas tecnológicas como a supervisão e censura de websites, além de cidades inteligentes com sistemas de reconhecimento facial e a utilização de um modo de pontuação de seus cidadãos.

Portanto, existe uma natureza paradoxal na Internet: ao começo da construção da Cibernética como uma teoria da informação, que previa que algo semelhante à rede, deveria ser a ferramenta que consubstancia uma liberdade irrestrita (sentimento que foi compartilhado pelos pioneiros da construção da Internet ), a própria natureza da rede faz com que a mesma possa ser um palco de manipulação, utilizando os interesses dos usuários como combustível.

Desta forma, uma das grandes garantias que pode ser disposta pela via normativa, a fim de angariar uma proteção a esses dados pessoais, e um melhor uso da Internet, é definir a proteção de dados não apenas como um direito, mas sim um direito fundamental, que deve ser aplicado de forma direta e exaustiva, de modo a proteger a sociedade de se retroalimentar com seus próprios interesses e vieses.

\section{O INÍCIO: A TRANSFORMAÇÃO TECNOLÓGICA}

\section{Do Analógico para o Digital}

Há cerca de sete mil anos surgia aquilo que viria a ser convencionado como o "primeiro computador da história": o ábaco. Diferentemente do que se pode pensar, o 
ábaco foi a primeira máquina construída com o intuito de realizar cálculos, e, em virtude da necessidade de representação matemática, foi replicado em diversas culturas.

Após, a feitura de outros tipos de máquina para realizar operações e otimizar o tempo humano foi crescendo. Foi com George Boole que a possibilidade lógica de uma criação da engenharia que pudesse realizar operações maiores, se transformou em realidade (MARTINS, 2009).

Estudando operações matemáticas, Boole criou um sistema simples e simbólico de representação: a Lógica de Boole, que utiliza um sistema numérico binário. Esse sistema é composto de dois números: 1 e 0 , onde o zero representa "falso" e o um representa "verdadeiro". Essa é a base lógica operacional de todos os computadores, inclusive os atuais.

Foi somente por conta dessa implementação de uma lógica representativa usando apenas dois valores, que se pode transformar em realidade o protótipo de uma máquina computacional como hoje conhecimentos. Quando se utiliza o computador, os dados colocados na máquina são convertidos de decimal para binário, forma a qual é entendida pelo computador, e assim, ele pode realizar operações.

Apesar da lógica booleana ter sido o salto de expertise que fez o conceito de computadores poder ser uma realidade, foi Alan Turing quem trouxe a demonstração teórica dos princípios do computador moderno (LOVELUCK, 2018). Nas ideias de Turing, ele formalizou o conceito de algoritmo, onde estabelecia que, tudo que pode ser calculado, também pode ser mecanizado, construindo, portanto, as bases da ciência computacional.

Com a eclosão da Segunda Guerra Mundial, a ideia da ciência computacional foi colocada em prática, com a necessidade de obter uma máquina que pudesse automatizar os processos de criptoanálise e quebrar os códigos da máquina alemã, denominada de Enigma.

Após essa apresentação, conceitualiza-se, portanto, o que vem a ser, especificamente, um computador. A princípio, é uma máquina que executa programas, ou seja, comandos gravados de forma prévia (LOVELUCK, 2018), possibilitando, portanto, que a máquina venha a transformar ou organizar algum tipo de informação.

O uso da lógica, e a possibilidade de criar uma máquina que fosse autônoma dos processos físicos, determinou que se houvesse a possibilidade de indicar uma construção que tivesse menos como base um arcabouço físico, e sim, a emergência de um nível autônomo de lógica, de uma forma semelhante à própria base neural de um ser humano. 
No que concerne à internet, suas origens são militares, especificamente no contexto do Departamento de Defesa dos Estados Unidos, que criou a Agência ARPA, a qual se fixou no estudo relacionado a pesquisas tecnológicas. Com base nos estudos, foi criada a primeira rede interativa e distribuída, a ARPANET (LOVELUCK, 2018). O grande diferencial, era que essa tecnologia de comunicação não detinha uma rede central específica, e transmitia suas informações através pacotes de dados, por meio de protocolos. No contexto de uma guerra, era um avanço nas comunicações, posto que a mensagem poderia chegar ao destino, mesmo que a origem fosse destruída.

Com a desmilitalização da descoberta, e a sua colocação no mercado, houve a união de um mundo onde as máquinas já estavam avançadas em seus sistemas lógicos, e a descoberta de um modo de transmissão de informações que nunca foi visto, mudando radicalmente a maneira de se realizar a comunicação.

\subsection{Cibernética}

A integração homem-máquina, é um pensamento bastante antigo. Muitos filósofos já imaginavam na antiguidade a definição de uma máquina humanesca, ou de um homem-máquina. Em 1948, o matemático Nobert Weiner publicou seu livro "Cybermetics: or the Controle and Communication in the Animal and the Machine", trabalho que é o início daquilo que seria considerado como "Cibernética".

O trabalho de Weiner foi fruto de uma pesquisa multidisciplinar, com interação em diversas áreas, como a biologia, a física, a psicologia, a matemática, a ciência política, dentre outras. Parte do pressuposto que determinadas funções de controle e de processamento de informações são semelhantes em máquinas e em seres vivos. Desta forma, essa semelhança pode ser reduzida a um modelo, que está sob o manto das mesmas leis matemáticas (KIM, 2004).

A Cibernética, portanto, é uma teoria informacional, que inclui não apenas o estudo da linguagem, mas também o estudo das mensagens como meios de dirigir a maquinaria e a sociedade, assim como desenvolvimento de máquinas computacionais outros tipos de autômatos, utilizando-se, uma base não somente de engenharia, mas também com reflexões que partem a partir de biologia e psicologia. (WEINER, 1948).

O começo físico desse inicial teórico, foi a tentativa de programas máquinas, no contexto da Segunda Guerra Mundial, para controlar artilharia antiaérea. A fim de criar uma máquina para esse fim, pôs-se a realizar um estudo acerca de um sistema 
eletromecânico que fosse desenhado a fim de usurpar uma função humana, como a capacidade de prever a trajetória de uma aeronave (WEINER, 1948).

Com os estudos para esse criação, Weiner e os demais pesquisadores da época, começaram a perceber as semelhanças entre os circuitos elétricos de uma máquina, e o próprio funcionamento do ser humano, formulando, assim, a base para uma teoria da informação aplicável tanto aos organismos vivos e às máquinas, quanto para a organização social, com uma aliança entre informação e biologia, colocando a informação como fonte de poder (LOVELUCK, 2018).

Nesse contexto, um quadro descritivo comum aos seres humanos, animais e máquinas, poderia ser estabelecido para permitir a elaboração de uma tipologia unificada de seus comportamentos, em virtude de determinadas finalidades, com os eventos exteriores suscetíveis de modificar um objeto e as mudanças produzidas pelo objeto em seu ambiente (input e output), importando como a informação circula no cerne de determinado sistema, podendo ajustar de maneira permanente o seu comportamento.

Desta forma, com o avento da Internet, é que a Cibernética volta ao enfoque, apresentando Weiner como o ator de uma utopia da comunicação, onde a Cibernética seria principal fonte, e a Internet, sua consagração, demonstrando como o mundo social humano pode sofrer grandes mudanças comportamentais, em virtude da maneira como e quando a informação é transmitida, e com a demonstração dessa união cada vez mais natural entre homem e máquina (LOVELUCK, 2018).

\subsection{A internet na sociedade: Cibercultura e Sociedade em Rede}

O mundo sempre se encontra em um processo de mudanças. No entanto, o que se encontra de novo e no centro desse paradigma da transformação, é a influência da tecnologia, especialmente no que tange à comunicação e à informação, que não apenas interfere de forma marginária na mudança social, mas sim, está no cerne da nova sociedade.

Foi o sociólogo Manuel Castells, que, em seus estudos, determinou que a sociedade atual não seria somente a Sociedade da Informação, posto que a Internet consubstanciou uma mudança muito mais profunda do que os outros meios ou tecnologias. Difere-se essa nova configuração social, pela sua arrumação em "redes" ao invés de autoridades centrais, não apenas relacionando-se à intercomunicação social, mas também à própria definição de poderes como o Estado e as empresas, com transcendência 
de fronteiras, descentralização e redefinição de velocidade das informações (CASTELLS, 2000).

A nova sociedade encontra-se conectada a um nível global, modificando também a forma de governar dos Estados, que também necessitam de mudanças para transformar sua organização que era nacional e verticalizada, a fim de dialogar com os conceitos de governança e partilhamento de soberania, reconfigurando a ideia de soberania geopolítica.

Essa nova estrutura social, baseada em redes por tecnologia e comunicação, nesse ecossistema de múltiplos "nós" conectados (CASTELLS, 2000), modifica a ideia de autoridade central, em várias formas e maneiras de estar social, posto a existência de uma conjunção de relações em teia, com a possibilidade da interrelação entre agentes de poder e sociedade, minimizando o grau de hierarquização, ao menos de maneira aparente. As relações de trabalho e poder começam a ser repensadas, aumentando o grau de participação, assim como os sistemas de referências pessoais mudam com uma velocidade nunca percebida nos demais momentos históricos, inferindo que a sociedade, vista como pensamento uníssono, tem sua estabilidade relativizada, com a lógica das redes modificando de forma estrutural os resultados de experiência, poder e cultura.

A tecnologia se torna, portanto, a indicação do que seja a própria sociedade, compreendida por meios de suas ferramentas e de como os atores sociais as utilizam, reorganizando e modificando a visão de mundo dos usuários, demonstrando o grande poder, não apenas revolucionário e de mudanças sociais, mas também manipulativo que emerge da utilização dessas ferramentas.

Nesse toar, percebe-se que, se a sociedade mudou radicalmente, também a cultura sofre grandes revoluções com o advento da era digital. O crescimento do ciberespaço resulta de um momento internacional onde existem formas de comunicação diferentes daquelas que as mídias clássicas propõem, com a abertura de um novo espaço de comunicação, que surge da interconexão mundial dos computadores. Por cibercultura, tem-se que é o conjunto de técnicas, prática e atitudes, modos de pensamentos e valores que se desenvolvem juntamente com o crescimento do ciberespaço (LÈVY, 1999).

O mundo virtual, portanto, é um ambiente envolto em intensas interações, que conseguem modificar o modelo de realidade em volta, tornando-se um vetor de inteligência e criação coletivas, dando ensejo a um novo tipo de universal, sem que exista alguma totalidade central ou hierarquizada. Não é o fato de existir uma cultura universal, mas sim, várias culturas de forma universal, em todas as partes. 
Três princípios básicos orientam o crescimento inicial do ciberespaço: a interconexão, a criação de comunidades virtuais e a inteligência coletiva (LÈVY, 1999). Nesse contexto, a cibercultura expressa uma mutação fundamental da própria essência da cultura, com o conceito de universalidade sem recair na regra da totalidade.

Portanto, observa-se que essa sensível mutação do conceito de sociedade perante as novas tecnologias é a realidade, com uma mudança de razões que eram dispostas como uma regra fechada, a todo momento observa-se uma nova faceta do conceito civilizatório integrado à rede, não devendo, portanto, o Direito ou as ciências (sejam elas sociais ou não) ficarem inertes a isso.

\section{DIREITOS FUNDAMENTAIS E LIBERDADE DE EXPRESSÃO}

\subsection{O conceito de Direitos Fundamentais}

O conceito de superioridade da matiz constitucional, é de extrema importância para a consecução da proteção de direitos a membros de uma mesma sociedade de forma igualitária. A noção de direitos fundamentais pode ser definida como um sistema de relações jurídicas básicas entre indivíduo e o Estado, fundamento de toda a ordem jurídica (FERNANDES, 2017). São a forma física da proteção (ou abstenção) estatal, frente à sociedade, frutos de lutas pelo reconhecimento desses direitos.

No que concerne a classificação dos direitos fundamentais a definição dada por Paulo Bonavides (2011), é aquela utilizada em larga escala, no que concerne o ordenamento jurídico brasileiro. O dito autor categorizou em gerações de direitos fundamentais. Abre-se aqui um adendo para demonstrar uma crítica doutrinária moderna ao uso da palavra "gerações", visto que pode caracterizar a ideia de abandono das conquistas da geração anterior, sendo a palavra "dimensão" a escolhida para retratar melhor essa classificação.

Por direitos de primeira dimensão, tem-se que são os direitos de liberdade (civis e políticos), os quais são aqueles direitos que deveriam ser primeiro positivados, haja vista serem retratadores do ideal da liberdade burguesa frente o absolutismo estatal. Após, falase no surgimento dos direitos de segunda dimensão, quais sejam: os direitos sociais, culturais e econômicos, abarcando a noção de igualdade, exigindo do Estado prestações materiais. Ao final do século XX, cunhou-se o pensar de uma nova dimensão de direitos fundamentais, a terceira, a qual abarca os ideais de direitos que têm como destinatários 
todo o gênero humano, transindividuais, ou seja, o direito ao desenvolvimento, à paz, ao meio ambiente.

É no diapasão do reconhecimento de outras dimensões de direitos humanos, que este trabalho encontra o marco inicial para seu deslinde. Apesar de haver divergências doutrinárias ao que seriam os direitos de quarta e quinta dimensão dos direitos fundamentais, Paulo Bonavides declara que o fator histórico dos direitos quarta dimensão seria a globalização política o que os definiriam como: a proteção do direito à democracia, à informação e ao pluralismo.

É no direito de quinta dimensão, segundo os ensinamentos de Augusto Zimmermann (2002), que se encontra o escopo principal deste projeto. De acordo com o autor, são direitos de quinta dimensão aqueles que inerentes à realidade virtual, compreendendo o grande desenvolvimento da internet.

Não é difícil de vislumbrar o porquê de haver doutrinadores colocando a internet como uma dimensão de direitos fundamentais. A revolução tecnológica remodelou a base material da sociedade, de forma a ser indissociável da mesma. O avanço das máquinas deixou de ser algo elitista ou privativo a temas de ficção científica, para ser algo do cotidiano, levando ao fato de que os processos de existência social e coletiva são moldados diretamente pelo meio tecnológico (CASTELLS, 2000).

Hoje em dia, o movimento geral de virtualização afeta não apenas a informação e a comunicação, mas também aos corpos, ao funcionamento econômico, aos marcos coletivos da sensibilidade e o exercício da inteligência. A virtualização alcança inclusive as formas de estar junto, a formação do "nós": comunidades virtuais, empresas virtuais, democracia virtual, etc. (LÉVY, 1998).

A internet se apresenta como um "eu" descentralizado. Um local onde um indivíduo pode descobrir semelhantes, criar projetos, aumentar a rede de conexões, exercer seu ofício. No cyberespaço a noção de minoria é reduzida, e começa a haver uma pluralidade de semelhantes reunidos em prol de um objetivo comum. Não há espaço que coloque a funcionar as engrenagens do reconhecimento, como o espaço virtual. A integração social nesse ambiente foi tamanha, que hoje há pouco espaço para delimitação de o que é real e o que é virtual. São todos parte da universalização do indivíduo.

\subsection{Liberdade de Expressão}


Após a introdução acerca dos direitos fundamentais, cabe falar especificamente acerca da conceituação em que consiste a liberdade de expressão, como um direito tal.

A liberdade, em sentido lato, é descrita como um dos pilares valorativos da humanidade, sendo o pressuposto da noção da cidadania. $\mathrm{O}$ homem tem a necessidade de ser livre por natureza, sendo um poder de autodeterminação, reconhecido pelo Estado e positivado em suas constituições de forma embrionária.

No começo do século XVIII, buscou-se a formulação de um pacto normativo, uma Constituição nos moldes que hoje se conhece, a qual se ligava diretamente às garantias da proteção de uma liberdade burguesa, com as características quais: reconhecimento e proteção de direitos fundamentais, divisão de poderes e participação do povo no Legislativo por meio de uma representação popular.

A fundamentação da construção de um Estado em modelo de garantia das liberdades, é a luta da burguesia contara o Estado absolutista, sendo, portanto, uma definição que parte dos fundamentos de uma segurança jurídica e da certeza do direito, na implementação de mecanismos de freio dos poderes e da proteção dos direitos burgueses, fincando seus aspectos econômicos na filosofia de Bentham, com a célebre teoria do laissez faire.

Observa-se, portanto, que a liberdade é a primeiro direito a ser conquistado por um povo, considerando a afirmação de que esta é um valor essencial à condição humana. Segundo os gregos, a liberdade era uma prerrogativa conferida aos cidadãos de participar das decisões políticas, diferenciando-se, portanto, do conceito de liberalismo clássico (COULANGES, 1971).

Alguns autores como Isaiah Berlin (1981) apresentam duas facetas para o conceito de liberdade: a negativa, que seria opositora a qualquer tipo de ingerência, e a liberdade positiva, definida como participação política, devendo, no entanto que o usufruto dessa liberdade venha em conformação com a coletividade, onde os indivíduos passem a exercer seu direito de autodeterminação dentro de um ideal da sociedade em que estão inseridos.

Nesse toar, a liberdade de expressão pode ser entendida como um conjunto de direitos relacionados à liberdade de se comunicar e de se informar, tendo, portanto, uma dupla faceta. $\mathrm{O}$ direito de expressar-se de forma livre reúne liberdades fundamentais que devem ser asseguradas de forma conjunta para garantir a total liberdade de expressão.

A liberdade de comunicação consiste em um conjunto de direitos, formas, processos e veículos, que possibilitam a coordenação desembaraçada da criação, 
expressão e difusão do pensamento e da informação, compreendendo as formas de criação, expressão e manifestação do pensamento e de informação, e a organização dos meios de comunicação, como depreende-se do conteúdo do art. $5^{\circ}$ da Carta Magna Brasileira (SILVA, 2000).

O direito de liberdade de expressão deve ser considerado como um direito fundamental, um verdadeiro princípio constitucional, norteador das técnicas interpretativas constitucionais (ALEXY, 2001). No entanto, é primordial dizer que falar em liberdade de expressão não é dar uma carta branca para se comentar em absoluto tudo o que se quer dizer ou fazer aquilo que quiser. A proteção constitucional não se estende à ação violenta, sendo, portanto, a liberdade de manifestação limitada por outros direitos e garantias fundamentais.

Como bem explica Alexy (2001), quando existe uma colisão de princípios fundamentais, deve-se levar em consideração a atividade de ponderação, a fim de tratar esses casos mais complicados. No constante à liberdade de expressão em colisão com a privacidade, por exemplo, pode-se garantir a primeira em detrimento da segunda a depender do caso em concreto, utilizando-se do argumento de que uma afronta à liberdade de expressão caracteriza-se em censura, conquanto a privacidade, quando ferida, pode ser reparada por meio de ações indenizatórias.

Portanto, observa-se que a liberdade é um dos direitos corolários de um Estado Democrático de Direito. E não se pode falar em liberdade, sem averiguar a proteção à liberdade de expressão, sendo esta analisada em seus dois planos: a liberdade de se informar, e a liberdade de se expressar. Portanto, uma sociedade que não consegue dispor de todas as informações necessária para conseguir se autodeterminar escolhendo aquilo que será melhor para si, não é uma sociedade livre.

Em tempos de uma Sociedade em Rede, altamente tecnológica, em com situações e padrões mercadológicos dentro da própria internet, indaga-se a respeito da própria noção de liberdade no contexto de uma cibersociedade.

\section{A CIBERSOCIEDADE E LIBERDADE DE EXPRESSÃO: A BOLHA DE INTERESSES NO ESPAÇO VIRTUAL}

\subsection{Capitalismo de Vigilância}


A internet se consubstancia na base tecnológica para a nova forma organizacional na Era da Informação. Por essa nova forma, temos que seria exatamente a rede. Por rede, entende-se não apenas no sentido técnico da palavra, mas sim, de forma mais abrangente, no sentido de conexão, inclusive, falando de interconexão subjetiva entre pessoas.

A procura por conexão social é uma prática de sobrevivência evolutiva. Sempre houve a busca de viver entre iguais, e de extrair dessas convivências, laços afetivos. Com a internet, essa conexão tornou-se cada vez mais fácil, e cada vez mais rápida, quase que instantânea. Não é difícil, portanto, perceber que não havia nenhum modo pelo qual os potenciais da internet não se achassem em pleno desenvolvimento, na sociedade. A internet é um meio de comunicação que permite, pela primeira vez, a comunicação de muitos com muitos, num momento escolhido, em escala global (CASTELLS, 2000).

A velocidade da transformação fez com que ficasse difícil de prever as mudanças estruturais que ocorreriam com a internet disseminada em escala mundial, e com tanto alcance. A projeção do futuro, por vezes se baseava em uma distopia dissociada da realidade, mais parecida com os livros de ficção científica. O grande diferencial da tecnologia, especialmente de uma tecnologia informacional como a internet, é que não existe um momento de ruptura, um momento de transformação que seja palatável. Enquanto se espera por um momento específico que mudança, ele já aconteceu, e está indo em direção a um novo modelo.

Portanto, até se perceber o que estava acontecendo, as práticas determinadas no presente capítulo, já estavam enraizadas no cotidiano digital, sem que a maioria das pessoas pudesse analisar o real perigo das novas práticas.

O termo "capitalismo de vigilância" tem suas origens mais determinadas, nas pesquisas de Shoshana Zuboff. Para essa autora, o diferencial dessa nova faceta do capitalismo, é exatamente o fato de usar o comportamento humano (e não a mão de obra) como meio de produzir lucro e controle de mercado. O modo mais claro de fazer isso, é por meio de tecnologias digitais, onde se vigia e prevê o comportamento humano, tendo bases, portanto, para, com esses dados, modificá-lo.

O diferencial nesse modelo é justamente o uso de dados dos usuários (geralmente a captação de dados é feita de forma não clara), buscando uma padronização, um modelo preditivo de comportamento, a fim de, ao mesmo tempo, saber exatamente qual o hábito de determinada pessoa, e também poder manipula-lo, ao ponto de modificar esse mesmo hábito, com fins determinados. 
É importante frisar que o capitalismo de vigilância não significa tecnologia. Muitas vezes, a captação de dados é colocada como pressuposto para que determinada ferramenta ou determinado produto, funcione. O que se coloca aqui, como capitalismo de vigilância, é uma nova forma de mercado, que não encontra vida fora da tecnologia, mas não é "a" tecnologia em si. Imperativos comerciais não são a mesma coisa que necessidades tecnológicas.

Portanto, usando movimentações tecnológicas como, por exemplo, a análise massiva de dados (big data), essa forma de capitalismo busca predizer e modificar o comportamento humano, como forma de produzir lucro e controle de mercado, não apenas impondo a informação, mas também produzindo a informação em escala massiva.

As primeiras facetas da hegemonia e controle de mercado que começam a se delinear, podem ser vistas de forma concreta, levando em consideração o Google, considerado como percussor desse novo movimento, como exemplo. De acordo com o projeto Atlas of digital hegemony, que desenvolve um estudo acerca do controle digital, o gigante do mecanismo de buscas, é o mais usado em quase todos os países do mundo, com exceção da China.

Aqui, demonstra-se um aspecto especial dessa nova sistemática, que é justamente a busca pela hegemonia. Se algo se torna o status quo informático, ele adquire o potencial de coletar mais dados, operando de forma a capturar todo aspecto do cotidiano de uma pessoa, a qual, muitas vezes, submete de forma "voluntária" (aqui a expressão encontrase em aspas, visto que a submissão é voluntária, porém o uso dos dados muitas vezes encontra-se obscuro, por isso não se pode dizer que existe uma voluntariedade completa) por meio das redes socias.

E o que acontece com esses dados? Eles podem ser coletados em prol da própria rede em si, como o Google sabendo seus hábitos de pesquisa e moldando os resultados das buscas para algo mais apelativo, como também podem ser vendidos a terceiros, com fins comerciais. Ou, ainda de forma mais assustadora, entregue a agências governamentais, como por exemplo, serviços de inteligência.

Essa nova lógica é sedutora, e muito mais difícil de ser detectada, visto que ela explora as necessidades de forma muito concreta, promovendo informação ilimitada e maneiras de antecipar o que as pessoas querem, de forma fácil e simples, sendo que esse novo mercado é uma lógica diferenciada, onde a vigilância e os padrões comportamentais são transformados em lucro (ZUBBOF, 2019). 
O capitalismo de vigilância se baseia em uma assimetria de conhecimento. Pela primeira vez, há maneiras possíveis de se obter uma quantidade de dados sobre determinadas pessoas, e, não apenas isso se pode processar, analisar, padronizar e prever comportamentos de acordo com esses dados. No entanto, não é apenas para o mercado que esses dados são usados. Com a previsão de padrões comportamentais, surge uma maneira de ter o controle deles, e modificá-los, de forma que não há nem a percepção do que está acontecendo. $\mathrm{O}$ que pode comprometer até mesmo a ideia de democracia, visto que os dados podem ser manipulados em prol de um fim comercial, e até mesmo político.

Uma das principais polemicas a colocar um holofote sobre como os dados dos usuários são capturados, refere-se ao escândalo do Facebook e da empresa Cambridge Analytica. A empresa referida teria usado dados disponíveis na rede social, a fim de traçar perfis de eleitores nos Estados Unidos. No entanto, foi noticiado que os dados usados foram obtidos de forma ilegal.

Em 2014, um teste de personalidade inofensivo, teve sucesso na rede social. O funcionamento é bem simples: os usuários, ao realizar o teste, dentro da plataforma do

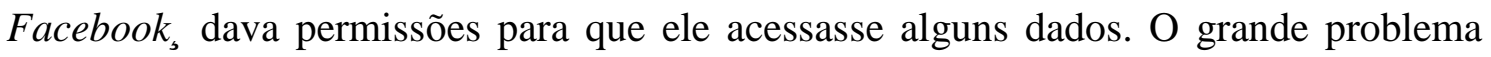
começa a partir do momento que não se dá uma atenção especial para o tipo de acesso que determinado programa ou aplicativo pede. Assim como os termos e condições, os acessos de terceiros contém fatos que, se fossem mais públicos, provavelmente não seriam permitidos por todos.

No caso em questão, o teste requisitava acesso não apenas aos dados de quem o fazia, mas também de toda a rede de contatos do usuário. Nesse contexto, esses dados foram vendidos para a empresa Cambridge Analytica, de forma que ela agora detinha informações sobre cerca de 50 milhões de pessoas que se encontravam com cadastro no Facebook . De porte desses dados, a empresa conseguiu realizar a análise e traçar padrões psicológicos, criando uma campanha digital hiper-segmentada para seus clientes, especialmente o que viria a ser o presidente norte-americano, Donald Trump, oferecendo aos eleitores, publicidade distribuída no Facebook em forma de anúncios patrocinados no feed.

Desta forma, pode-se apresentar que, pela primeira vez, tem-se registro de uma mudança específica em uma manipulação eleitoral, por meio da captura de dados e projeção de perfis. Ao levarmos em consideração que as eleições, consubstanciada pelo ato de votar, é um dos pilares de um Estado democrático, quando se está diante de uma forma de alienação sorrateira, com base em uso de dados que nem ao menos foram 
coletados de forma pública e consentida, tem-se que a própria esteia democrática se encontra em risco.

A sociedade se encontra muito atrasada em relação à essa nova forma de exploração, especialmente porque ela seduz no contorno da facilidade e da individualidade de seus produtos e serviços. Tão importante quando uma questão de saber o que está acontecendo, deve-se cuidar para que o véu da facilidade caia, e que seja demonstrado que a própria individualidade e autonomia comportamental estão sendo colocadas em risco, tudo isso pela facilidade de ter um produto específico em uma propaganda já direcionada.

Aos poucos existe um movimento de contenção de danos. Há uma importância maior no cenário mundial (e também nacional), com a proteção de dados individuais. Esse assunto será tratado com mais profundidade no capítulo posterior, quando irá haver uma incursão de proteção social nessa nova sistemática.

\subsection{Colonialismo Digital}

A datificação da sociedade não remete apenas a uma nova forma de capitalismo, mas também a uma nova forma de colonialismo. Essa nova ordem cria a dependência de plataformas, as quais usam os dados para continuar a recriar o círculo de dependência, assim como uma nova forma de descriminação social.

Se no passado os impérios definiam seu controle por meio da ocupação de rotas e matérias-primas, a nova forma de dominação é por meio do uso da tecnologia, dados e poder computacional. Muito se fala acerca dos dados serem o novo "petróleo", no entanto, diferentemente do combustível fóssil, a extração de dados é feita de maneira muito menos definida e contornada. Na verdade, muitas vezes nem existe o conhecimento de que essa extração está ocorrendo.

A luta entre controle e liberdade não é nova, mas diferentemente do passado, não existe a noção de que não há liberdade na internet, até o momento de ela deixar de existir completamente, posto que todas as engrenagens rodam de modo encoberto. E não apenas isso, mas, dessa vez, os donos do poder não se encontram em Impérios e Países, mas sim em empresas. A colonização ocorre precipuamente no Vale do Silício, e até mesmo os Estados estão sob controle do poder tecnológico de poucos. Nesse momento de dominação global, existe a penetração em governos, em movimentos dos cidadãos, em predição de comportamentos de todos que se encontram, de alguma forma, conectados. 
E se a tendência é a conexão global, então pouco se pode fazer para mudar esse cenário, a não se que as atitudes comecem a ocorrer agora.

Sartre (1968) define o colonialismo enquanto sistema econômico, atuando conforme os interesses e necessidades, com objetivos de explorar os recursos sociais e naturais da colônia, em benefício do colonizador. É um dos parâmetros da colonização também, impor os parâmetros de diferenciação e hierarquia, além da ideia de que há uma necessidade da colônia, em ser colonizada. Explica-se: com a ideia de hierarquia, pressupõe o fato de que existe um poder maior (no caso, o ator explorador). Incutindo essa ideia, ajuda a conceituação de que existe algo em troca, como por exemplo, ajudar a construir casas em prol de uma extração de recursos minerais em determinada localidade. Há uma falsa percepção da realidade.

Quando tratamos dos ambientes digitais, percebe-se que não é muito diferente. Os recursos de dados são extraídos de forma exploratória, manifestando-se em uma conotação de controle. O colonialismo digital comina as práticas predatórias extrativistas, com a quantificação abstrata da internet (COLDRY, 2018.), criando uma situação de dependência.

Existe uma extração racional, que trata da extração de dados de maneira que não há valor na mesma, é apenas um compartilhamento, operando na sociedade ao ponto de apresentar que as pessoas se beneficiam dessa manifestação na rede. Ou seja, não existe nada de ruim no fato de uma pessoa compartilhar sua localização, sendo que ela irá se beneficiar com um cupom de desconto para almoçar em um local perto de onde esteja, por exemplo. É justamente nesse contexto que o colonialismo digital é talvez mais perigoso que os demais: porque não é tão perceptível. Pode-se perceber que as florestas estão acabando, mas é muito mais difícil de descobrir que existe uma manipulação comportamental pelo uso de dados extraídos de uma plataforma digital.

Os principais atores do colonialismo de dados (ou colonialismo digital) podem ser denominados de "setores de quantificação social", que sãos as corporações envolvidas em capturar o dia a dia e transformar em dados quantificados que são analisados a fim de gerar lucro (COLDRY, 2018). Podemos citar empresas como Amazon, Facebook e Google no ocidente, e grandes como Baidu e Alibaba no oriente, mais precisamente na China. Apesar de haver essa divisão entre oriente e ocidente, percebe-se que ela não se mantém de forma essencial, visto que, basicamente, essas empresas atuam em todos os locais, em virtude da falta de fronteiras quando se fala em atuação pela internet. 
As grandes corporações, detentoras das fronteiras tecnológicas, usam todas as ferramentas à sua disposição para centralizar os serviços de internet, vigiar seus usuários, processar seus dados, e usar esses mecanismos para fazer com que esses continuem reféns de seus serviços. A população, por sua vez, se encontra pouco preocupada com essa questão, posto que concorda com esses abusos, visto que, em contrapartida, utiliza serviços gratuitos e que melhoram sua experiencia.

\subsection{A proteção de dados como garantidora da liberdade de expressão}

De acordo com o descrito por Stefano Rodotà (2008), há um tipo de esquizofrenia social, política e institucional, sendo cada vez mais difícil, seja por questões técnicas ou culturais, respeitar a privacidade dos indivíduos, posto que as razões de segurança interna, interesses de mercado e reorganização da administração pública estão levando à dimimuição de proteção de garantias importantes ou até mesmo o desaparecimento destas (RODOTÀ, 2008).

Fala-se que os dados são o novo recurso, o novo petróleo da era digital. Não apenas para fins de mercado, mas também para fins de manipulação. As eleições brasileiras de 2018 foram consideradas um exemplo do uso da internet com esses fins, com a utilização massiva de ferramentas tecnológicas e fake news a fim de modificar o cenário político. Na sociedade de vigilância em que se vive, a informática transforma o cidadão em um homem de vidro, exposto em função da circulação de seus dados pessoais (RODOTÀ, 2008).

Por ser determinada com tantas atribuições, infere-se que os dados pessoais são uma extensão do próprio homem enquanto tal em sociedade, posto que revelam as características e desejos mais profundos. Com algumas ligações, pode-se determinar seu gosto musical, estético, artístico. Suas habilidades intelectuais, inspirações políticas e

opiniões sobre vastos assuntos. Toda essa junção, acaba por criar um panorama completo e nunca visto sobre os indivíduos. Saber é o primeiro passo para manipular.

Desde forma, a internet vai moldando sua apresentação. Quando um determinado like em uma rede social identifica a posição política, quase que instantaneamente propagandas de perfis ligados a ela, e websites a respeito do assunto começam a aparecer. Quanto mais cliques, menos plural fica a apresentação dos conteúdos online, posto que começa a empreender um perfilhamento necessário para capturar o usuário, mostrando conteúdos que ele com certeza vai querer ler. 
É nesse momento que a situação começa a sair do controle e passa a integrar um perigo real à liberdade de expressão, haja vista que passa-se não a apresentar os conteúdos por eles estarem presentes na rede, mas sim, seleciona-se os conteúdos de acordo com o interesse do usuário, fechando o leque informacional.

O que poderia servir para restringir essa violação?

O direito à autodeterminação informativa garante que a pessoa possa ter o controle das suas informações, tanto em seu aspecto positivo quanto negativo (SAMPAIO, 1998), sendo incluído no âmbito do direito à privacidade, determinando a construção de sua própria esfera privada.

O cidadão deve ser considerado parte hipossuficiente no contexto informacional, não podendo considerá-lo como um simples fornecedor de dados, mas também como um agente controlador desse fornecimento. O indivíduo teve ter o direito de aceitar fornecer esses dados, saber para que estão sendo usados, e como estão sendo compartilhados. É esse controle que se revela como o instrumento de equilíbrio na distribuição de poder da nova esfera social (RODOTÀ, 2008).

No cenário brasileiro, a Lei 13708/2018, determinada como Lei Geral de Proteção de Dados, traz um rol normativo de proteção às informações pessoais, devendo haver o consentimento para a utilização de dados sensíveis do indivíduo. Ademais, deve haver a transparência no uso destes dados, respondendo a questionamentos como "para quê e para quem", sendo encarado como expressão da liberdade, autodeterminação, regulamentação poder de vontade, para que possam ser melhores juízes de seus interesses (PERLINGIERI, 2008).

\section{CONCLUSÃO}

As implicações da sistemática da nova sociedade inserida em um contexto tecnológico e virtualizado, são muitas. Uma delas se conecta estritamente à importância de vislumbre de um perigo ante às liberdades fundamentais, notadamente, a liberdade de expressão.

Determinada como veículo máximo dessa liberdade, muitas vezes a Internet é considerada como a grande ferramenta garantidora de uma maneira de se expressar nunca observada em outras mídias ou tecnologias. Está-se diante de uma verdadeira aldeia global, cuja informação é determinada de forma distribuída e não centralizada, onde todos 
podem ser agentes divulgadores e receptores, não havendo uma autoridade central ou um foco de poder de transmissão.

No entanto, apesar dessa visão e do potencial, o uso da Internet como meio de manipulação da sociedade é uma das grandes tendências mundiais. Esse potencial para uso mercadológico foi concebido ainda de forma bastante intensa no começo da integração digital, com a utilização de propagandas em websites, e continuou crescendo e se sofisticando, até a materialização daquilo que se denomina hoje por "Capitalismo de Vigilância".

Porém não é apenas isso. A utilização da web para sugestionar em outras áreas, como em eleições, é uma ameaça a um dos grandes pilares modernos: a democracia. Nesse contexto, observa-se que hoje, nesse delineamento atual, a grande rede não é tão livre e plural como se pensa, porém, está repleta de propagandas, mensagens subliminares e o uso de tecnologias para determinar que a experiência digital seja apenas um espelho daquilo que o usuário já quer, ou do que outros grandes atores esperam que sejam.

Desta forma, a liberdade, configurada como um direito fundamental clássico e prioritário, encontra-se em risco de uma forma muito sutil. Não se pode considerar a Internet como um meio livre, quando as informações se aglomeram de acordo com interesses e não por razões técnicas. Destarte, deve-se perceber a importância da definição da proteção de dados como uma das grandes armas contra essa prática, considerando que pode dar um escudo a determinado usuário de se blindar contra o uso de seus dados, e, consequentemente, acarretar em uma abertura de rede menos enviesada e mais plural.

\section{REFERÊNCIAS}

ALEXY, Robert, Teoria dos Direitos Fundamentais, Tradução de Virgilio Affonso da Silva, $1^{\text {a }}$ Ed., Malheiros Editores, 2001.

BAUMAN, Zygmunt; LYON, David. Vigilância líquida. Rio de Janeiro: Zahar, 2013.

BERLIN, Isaiah. Quatro ensaios sobre a liberdade. Brasília: UNB, 1981.

BLUM, Renato M. S. Opice. Manual de Direito Eletrônico e Internet. São Paulo: Aduaneiras, 2006.

BONAVIDES, Paulo. Curso de Direito Constitucional. 26a edição. São Paulo: Malheiros. 2011. 
BORGES, Roxana Cardoso Brasileiro. Direitos da personalidade e autonomia privada. 2. ed. São Paulo: Saraiva, 2007.

BRANCO, Paulo Gustavo Gonet; BRANCO, Pedro Henrique de Moura Gonet. STRUCTURAL WAYS OF GOVERNING THE INTERNET -THE BRAZILIAN POSITION. Revista Juridica, [S.1.], v. 2, n. 55, p. 592 - 606, abr. 2020. ISSN 2316-753X. Disponível em: <http://revista.unicuritiba.edu.br/index.php/RevJur/article/view/3840/371372180>. Acesso em: 19 abr. 2020. doi:http://dx.doi.org/10.21902/revistajur.2316753X.v2i55.3840.

CASTELLS, Manuel. A sociedade em rede. São Paulo: Paz e Terra, 2000.

COULDRY, Nick e MEIJAS, Ulises. Data colonialism: rethinking big data's relation to the contemporary subject. Disponível em https://journals.sagepub.com/doi/abs/10.1177/1527476418796632?journalCode=tvna. Acesso em 20 de maio de 2019.

CONSELHO DA EUROPA. Carta dos Direitos Fundamentais da União Européia, de 18 de dezembro de 2000. Disponível em:< http://www.europarl.europa.eu/charter/pdf/text_pt.pdf>. Acesso em: 11 de nov. 2019.

CONSELHO DA EUROPA. Convenção de Estrasburgo para a proteção das pessoas relativamente ao tratamento automatizado de dados de caráter pessoal, de 1981. Disponível em: $\quad$ https://www.cnpd.pt/bin/legis/internacional/Convencao108.htm $>$. Acesso em: 12 de nov. 2019.

COULANGES, F. A cidade antiga. Tradução de Fernando de Aguiar. Lisboa: Clássica, 1971.

DOTTI, René Ariel. A liberdade e o direito à intimidade. Revista de informação legislativa, v. 17, n. 66, p. 125-152, abr./jun., 1980.

ECHTERHOFF, Gisele. Direito à privacidade dos dados genéticos. Curitiba: Juruá, 2010.

KIM, Joon Ho.Cibernética, Ciborgues e Ciberespaço: notas sobre as origens da cibernética e sua reinvenção cultural. Horizontes Antropológicos, ano 10, n.21. Porto Alegre, 2004.

LEONARDI, Marcel . Tutela e privacidade na internet. São Paulo: Saraiva, 2009.

LÉVY, Pierre. O que é o virtual. Rio de Janeiro: Editora 34, 1996.

LOVELUCK, Benjamin. Redes, liberdade e controle: uma genealogia política da internet. Petrópolis: Editora Vozes, 2018. 
EINALDO FILHO, Demócrito. Privacidade na sociedade de informação. Recife: 2006. Disponível em: <https://repositorio.ufpe.br/bitstream/123456789/4642/1/arquivo6028_1.pdf >. Acesso em: 12 de nov. 2019.

FERNANDES, Bernardo Gonçalves. Curso de Direito Constitucional, Salvador: Ed. JusPodivm. 2017.

PERLINGIERI, Pietro. O direito civil na legalidade constitucional. Rio de Janeiro: Renovar, 2008.

RODOTÀ, Stefano. A vida na sociedade de vigilância: a privacidade hoje. Rio de Janeiro: Renovar, 2008.

SARTRE, Jean Paul. Colonialismo e Neocolonialismo. Rio de Janeiro: Tempo Brasileiro, 1968.

SAMPAIO, José Adércio Leite. Direito à intimidade e à vida privada: uma visão jurídica da sexualidade, da família da comunicação e informações pessoais, da vida e da morte. Belo Horizonte: Del Rey, 1998.

SCHREIBER, Anderson. Direitos da personalidade. 2. ed. São Paulo: Atlas, 2013.

SILVA, José Afonso da. Curso de Direito Constitucional Positivo. 28 ed. São Paulo: Malheiros, 2006.

SILVA, Lucas Gonçalves da; CARVALHO, Mariana Amaral. Direito ao esquecimento na sociedade da informação: análise dos direitos fundamentais no meio ambiente digital. Revista Brasileira de Direitos e Garantias Fundamentais, v. 3, n. 2, p. 66-86, jul./dez., 2017.

STRENGER, Irineu. Da autonomia da vontade. 2. ed. São Paulo: LTr, 2000.

WEINER, Nobert. Cybernetics: or control and communication in the animal and the machine. Cambridge, Massachusetts: 1948.

ZIMMERMANN, Augusto. Curso de Direito Constitucional. 2.ed. rev.ampl. e atual. Rio de Janeiro: Lumen Juris, 2002.

ZUBOFF, Shoshana. Big Other: Surveillance Capitalism and the Prospects of an Information Civilization. Disponível em: http://papers.ssrn.com/abstract=2594754. Acesso em 18 de abril de 2019.

ZUBOFF, Shoshana. The Age of Surveillance Capitalism: the fight for a human future at the new frontier of power. Nova Iorque: Public Affairs, 2019. 